\title{
Candidate Effector Proteins of the Rust Pathogen Melampsora larici-populina Target Diverse Plant Cell Compartments
}

\author{
Benjamin Petre, ${ }^{1,2,3}$ Diane G. O. Saunders, ${ }^{1,4,5}$ Jan Sklenar, ${ }^{1}$ Cécile Lorrain, ${ }^{1,2,3}$ Joe Win, ${ }^{1}$ \\ Sébastien Duplessis, ${ }^{2,3}$ and Sophien Kamoun ${ }^{1}$ \\ ${ }^{1}$ The Sainsbury Laboratory, Norwich Research Park, NR4 7UH Norwich, U.K.; ${ }^{2}$ INRA, UMR 1136 Interactions Arbres/ \\ Microorganismes, Centre INRA Nancy Lorraine, 54280 Champenoux, France; ${ }^{3}$ Université de Lorraine, UMR 1136 Interactions \\ Arbres/Microorganismes, Faculté des Sciences et Technologies, 54506 Vandoeuvre-lès-Nancy, France; ${ }^{4}$ The Genome \\ Analysis Centre, Norwich Research Park, NR4 7UH Norwich, U.K.; ${ }^{5}$ The John Innes Centre, Norwich Research Park, NR4 7UH \\ Norwich, U.K.
}

Submitted 6 January 2015. Accepted 26 January 2015.

\begin{abstract}
Rust fungi are devastating crop pathogens that deliver effector proteins into infected tissues to modulate plant functions and promote parasitic growth. The genome of the poplar leaf rust fungus Melampsora larici-populina revealed a large catalog of secreted proteins, some of which have been considered candidate effectors. Unraveling how these proteins function in host cells is a key to understanding pathogenicity mechanisms and developing resistant plants. In this study, we used an effectoromics pipeline to select, clone, and express 20 candidate effectors in Nicotiana benthamiana leaf cells to determine their subcellular localization and identify the plant proteins they interact with. Confocal microscopy revealed that six candidate effectors target the nucleus, nucleoli, chloroplasts, mitochondria, and discrete cellular bodies. We also used coimmunoprecipitation (coIP) and mass spectrometry to identify 606 $N$. benthamiana proteins that associate with the candidate effectors. Five candidate effectors specifically associated with a small set of plant proteins that may represent biologically relevant interactors. We confirmed the interaction between the candidate effector MLP124017 and TOPLESS-related protein 4 from poplar by in planta coIP. Altogether, our data enable us to validate effector proteins from M. larici-populina and reveal that these proteins may target multiple compartments and processes in plant cells. It also shows that $N$. benthamiana can be a powerful heterologous system to study effectors of obligate biotrophic pathogens.
\end{abstract}

Plant pathogens secrete virulence proteins known as effectors to modulate host functions and sustain colonization (Dodds and Rathjen 2010). Determining how these effectors function is a key to understanding pathogenicity mechanisms and improving our ability to protect crops from disease. Accordingly, the study of these proteins, which is referred to as effector biology, has become a driving theme of research in molecular

Corresponding authors: Sophien Kamoun;

E-mail: Sophien.Kamoun@tsl.ac.uk; and Sébastien Duplessis;

E-mail: duplessi@nancy.inra.fr

*The $\boldsymbol{e}$-Xtra logo stands for "electronic extra" and indicates that eight supplementary figures and four supplementary tables are published online.

(c) 2015 The American Phytopathological Society plant pathology (Hogenhout et al. 2009). Whole-genome sequencing has revealed repertoires of hundreds of genes encoding predicted secreted proteins in fungal and oomycete plant pathogens (Kamoun 2007; Schmidt and Panstruga 2011). Many, although not all, of these secreted proteins are thought to function as effectors, modulating host structure and physiology. Whereas apoplastic effectors function in the host-pathogen interface, host-translocated (cytoplasmic) effectors enter plant cells, where they carry a diverse array of activities in various subcellular locations (Rovenich et al. 2014; Win et al. 2012).

A key question in effector biology is how effector proteins function inside host cells. To answer this question, it is critical to identify the host cell compartment that effectors target and the host proteins they associate with (Alfano 2009). Hosttranslocated effectors of fungal and oomycete plant pathogens have been reported to target a variety of subcellular compartments, such as the plasma membrane, tonoplast, vacuole, endoplasmic reticulum, nuclear compartments, and cytosol (Bozkurt et al. 2012; Caillaud et al. 2012; McLellan et al. 2013; Rafiqi et al. 2012). Bacterial effector proteins also accumulate in these compartments, but in addition, some Pseudomonas type-III effector proteins have been reported to accumulate in chloroplasts and mitochondria (Block et al. 2010; Jelenska et al. 2007; Li et al. 2014; RodríguezHerva et al. 2012). In plant cells, effectors can have enzymatic activities (Djamei et al. 2011) or associate with host molecules, such as nucleic acids and proteins (Mak et al. 2012). Host proteins that associate with effectors can be classified as helpers (facilitators) or targets (Win et al. 2012). Helpers are host factors that enable effectors to function, e.g., by mediating effector trafficking or maturation, whereas targets are the molecules modulated by the effectors to alter host processes (Win et al. 2012). Effectors perturb host targets in various ways. For instance, many effectors modulate the stability of their host targets whereas others act as inhibitors of the target enzymatic activity (Bos et al. 2006, 2010; Caillaud et al. 2013; Park et al. 2012; Wang et al. 2010; Xing et al. 2007). Effectors from evolutionarily unrelated pathogens can sometimes converge on the same host target (Mukhtar et al. 2011; Song et al. 2009; Weßling et al. 2014) but effectors can also disable effector-targeted pathways at different steps (Boller and He 2009; Win et al. 2012).

The functional investigation of genome-wide catalogs of candidate effectors requires high-throughput approaches commonly referred to as 'effectoromics.' Given that many effectors function in plant cells and that it is often not possible to deliver tagged effectors via the pathogen, a widely used assay consists 
of expressing candidate effectors directly in plant cells. Methods such as agroinfiltration (Agrobacterium tumefaciens transient transformation assay) and agroinfection (A. tumefaciens/ virus-mediated transformation) of Nicotiana benthamiana leaves have been extensively used (Du et al. 2014; Oh et al. 2009; Torto et al. 2003; Vleeshouwers et al. 2008; Wang et al. 2011). Notably, the large pavement cells of the abaxial surface of the leaves are particularly suitable for subcellular localization of fluorescently-tagged effector proteins by confocal microscopy (Caillaud et al. 2012; Schornack et al. 2010). Another method amenable to medium-throughput screens is the identification of interactors of effector proteins in planta, using coIP followed by liquid chromatography-tandem mass spectrometry (coIP/MS) (Bozkurt et al. 2011; Win et al. 2011).

Rust fungi (Basidiomycetes, Pucciniales) are a large group of fungal pathogens that collectively infect many plant families (Duplessis et al. 2012). Among the approximately 7,000 species of rust fungi, several are among the most devastating pathogens of crops and are a constant threat to agricultural systems and food security (Pennisi 2010). Although the Pucciniales are intensely studied (Dean et al. 2012), their obligate biotrophic lifestyle and the fact that they do not infect model plant species have precluded in-depth molecular investigations of their biology and pathogenicity mechanisms. As a consequence, only a handful of rust fungal effector proteins have been validated so far (Petre et al. 2014). They consist of small proteins with $\mathrm{N}$-terminal signal peptides that are expressed in haustoria and show no sequence similarity to proteins outside the Pucciniales (Garnica et al. 2014; Kemen et al. 2005; Rafiqi et al. 2010). These effectors appear to translocate inside host cells in which they accumulate in the nucleus or cytosol. However, we still do not know how they function in host cells and which host proteins they target (Petre et al. 2014).

Melampsora larici-populina causes leaf rust disease on cultivated poplars, and annual epidemics lead to considerable damage in plantations (Duplessis et al. 2009; Hacquard et al. 2011; Major et al. 2010). The analysis of the $M$. larici-populina genome revealed a large catalog of 1,184 small secreted proteins defined as having fewer than 300 amino acids and no transmembrane domains (Duplessis et al. 2011a). Among these secreted proteins, the most promising candidate effectors have been identified as lineagespecific, expressed during the biotrophic phase of leaf colonization, and having signatures of positive selection (Hacquard et al. 2010, 2012; Saunders et al. 2012). Notably, a set of 73 small secreted proteins that are expressed in haustoria or display sequence similarity to haustorially-expressed proteins from Melampsora lini is likely to be enriched in host-cell translocated effector proteins (Catanzariti et al. 2006; Hacquard et al. 2012; Joly et al. 2010).

In this study, we established an effectoromics pipeline to select, clone, and express $M$. larici-populina candidate effectors in $N$. benthamiana leaf cells to determine their subcellular localization and association with plant proteins. We highlight eight candidate effectors that either accumulate in distinct host subcellular compartments, specifically associate with $N$. benthamiana proteins, or both and which are high-priority proteins for further investigations. To validate the coIP/MS screen, we confirmed the association between one candidate effector, MLP124017, and the poplar TOPLESS-related protein 4 , confirming that $N$. benthamiana can be a powerful heterologous system to study pathogen effectors.

\section{RESULTS}

\section{Selection of candidate effector proteins \\ from $M$. larici-populina.}

To identify the most promising candidate effectors of $M$. laricipopulina, we selected small secreted proteins that fulfill the following three criteria: i) expressed in planta and in haustoria but not in spores, ii) no predicted function and no recognizable domain, and iii) no sequence similarity to proteins outside the Pucciniales (Fig. 1). After removing redundant family members, we obtained 16 genes that fulfill these three criteria. We added to the list eight proteins: MLP37347, MLP124266, MLP124530, and MLP123524 that encode homologs of validated effector proteins from other Pucciniales (AvrL567, AvrP4, AvrP123, and RTP1, respectively), MLP123731 and MLP106985, because they are strongly expressed during the biotrophic phase, and MLP124478 and MLP67606, because they belong to gene families with signatures of positive selection (Duplessis et al. 2011b; Hacquard et al. 2010, 2012) (Table 1). The final list consisted of 24 proteins that ranged in size from 72 to 256 amino acids (average 147) with 0 to 11 cysteine residues within the mature form (Table 1). Interestingly, 13 candidates are classified into protein families in M. larici-populina but have no sequence similarity to proteins in other species, suggesting a recent expansion in M. larici-populina. Only MLP123524, MLP124111, and MLP91075 show sequence similarity to proteins from Puccinia species.

\section{Candidate effectors accumulate in distinct subcellular compartments.}

To determine where the 24 candidate effectors accumulate in plant cells, we first cloned the coding sequence matching their mature form (i.e., without signal peptide) to obtain candidate effector-green fluorescent protein (GFP) fusions downstream of a $35 \mathrm{~S}$ promoter in an Agrobacterium tumefaciens binary vector. Next, we expressed the fusion proteins in $N$. benthamiana by agroinfiltration and determined their level of accumulation in leaf cells by confocal microscopy and immunoblotting. A total of 20 fusion proteins accumulated at detectable levels in leaves (Fig. 2; Supplementary Fig. S1). Immunoblotting experiments showed that 14 fusion proteins displayed a single band at the expected size, which confirmed their integrity. The six remaining fusion proteins showed bands that were higher or lower than expected, suggesting posttranslational or other modifications (Supplementary Table S1). In contrast, four fusion proteins showed no detectable fluorescent signals and no bands on the immunoblots (Table 1). Increasing the concentration of infiltrated bacteria only resulted in weak fluorescent signals, heterogeneously dispatched in few cells. Based on these data, we discarded these four proteins and retained only the 20 fusion proteins that accumulated at detectable levels in leaf cells for further investigation.

Of the 20 fusion proteins, six displayed an informative distribution of the fluorescent signal that markedly differed from the GFP control (Fig. 2A to F; Supplementary Figs. S2 and S3). First, MLP109567-GFP and MLP124478-GFP fluorescent signals accumulated in the nucleus and the nucleoli, respectively (Fig. 2A and B). Second, MLP124530-GFP and MLP37347-GFP signals accumulated in small bodies. MLP124530-GFP bodies formed preferentially in the nucleus (Fig. 2C; Supplementary Fig. S4). Although the bodies showed regular shapes, their size was variable. MLP37347-GFP bodies preferentially formed in the cytosol and were very variable in size, number, and shape (Fig. 2D). For these two fusion proteins, the brightness and irregularity of the bodies observed suggest that they might be artifactual aggregates. Third, MLP107772-GFP and MLP124111-GFP signals overlapped with chlorophyll, suggesting accumulation in chloroplasts (Fig. 2E and F). Whereas MLP107772-GFP signal in chloroplasts was strong, MLP124111-GFP signal was weaker and also accumulated in large, bright, and irregular cytosolic aggregates. For both proteins, no signal was detected in the cytosol and the nucleus. However, MLP107772-GFP also showed a weak signal in mobile cytosolic bodies. To investigate this further, we coexpressed MLP107772-GFP with ScCOX4-mCherry, a marker of plant mitochondria (Fig. 3) (Nelson et al. 2007). This revealed 
overlapping fluorescent signals indicating that MLP107772-GFP accumulates in mitochondria in addition to chloroplasts. The remaining 14 fusion proteins we tested showed an uninformative subcellular distribution in the nucleoplasm and the cytosol that was similar to the GFP control (Fig. 2G to T). We conclude that six of the candidate effectors we tested display an informative localization in $N$. benthamiana and accumulate in specific cell compartments (Table 1). These findings indicate that $M$. laricipopulina, similar to other plant parasites, is likely to deliver effector proteins to distinct host cell compartments.

In planta coIP assays reveal plant protein interactors.

To complement our cell biology findings and gain further insight into the role of the candidate effectors in plant cells, we used coIP/MS to identify plant protein interactors. Following expression of GFP-tagged candidate effectors in $N$. benthamiana by agroinfiltration, we immunoprecipitated protein extracts with anti-GFP antibodies, separated the protein mixtures by sodium dodecyl sulfate-polyacrylamide gel electrophoresis (SDS-PAGE), and digested the proteins with trypsin. Tryptic peptides were identified by mass spectrometry and were matched to a redundant set of 113,358 protein sequences constituting the predicted proteome of $N$. benthamiana. After filtering out duplicated or highly similar proteins, we obtained a final list of 606 nonredundant $N$. benthamiana proteins as potential interactors of the assayed M. larici-populina proteins. On average, a candidate effector associated with 124 plant proteins, ranging from 14 for MLP102036 to 413 for MLP105684 (Fig. 4A). Conversely, on average, a plant protein associated with four candidate effectors, ranging from 1 to 20 (Fig. 4B). A total of 138 proteins ( $23 \%$ of the dataset) were

A CANDIDATE EFFECTOR PROTEINS SELECTION

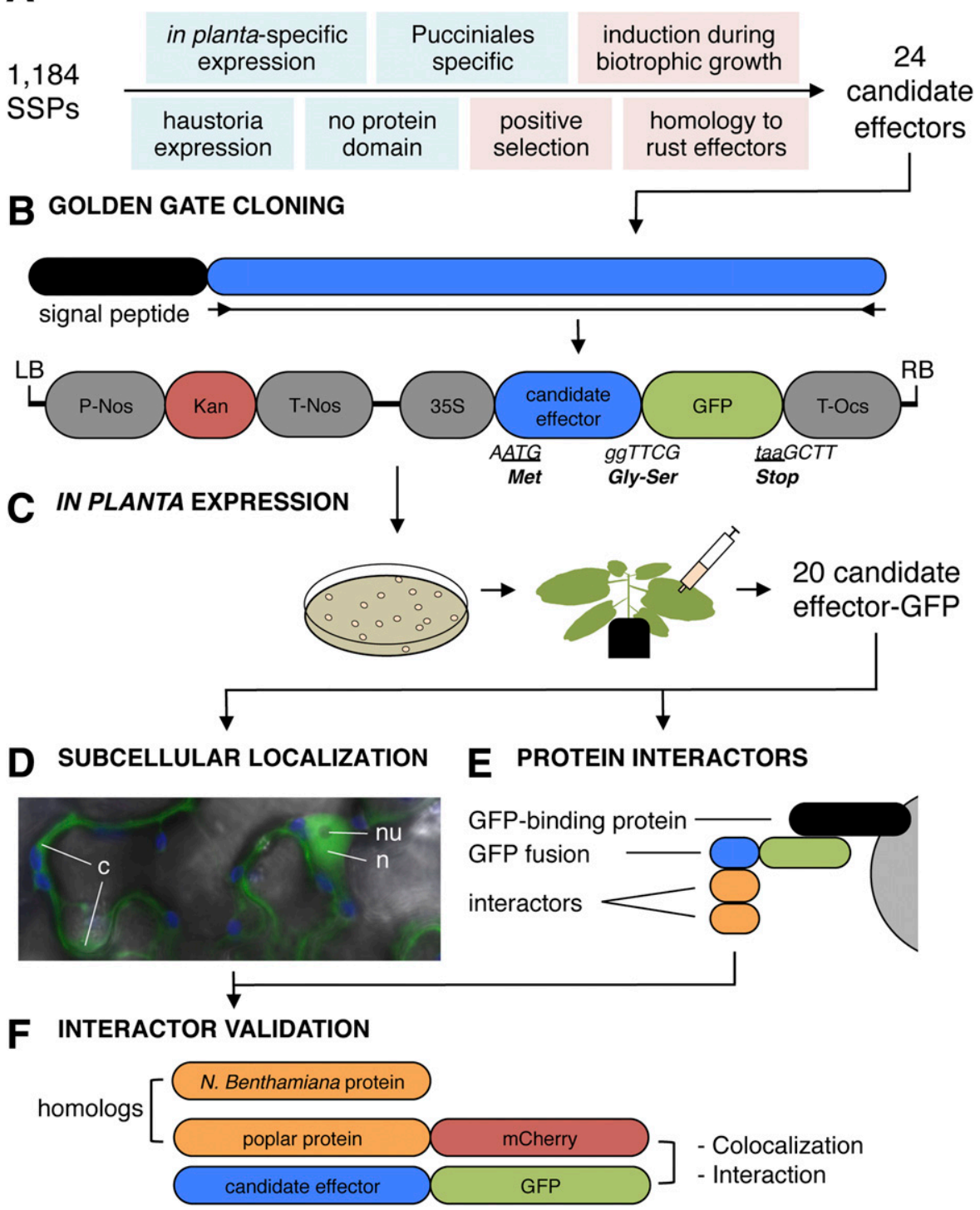

Fig. 1. Overview of the effectoromics pipeline. A, A total of 24 candidate effectors were mined from a set of 1,184 small secreted proteins (SSPs) with an automated pipeline (light blue) or manually (light red). B, The coding sequences of the mature form of the candidate effector proteins (blue) were cloned into a Golden Gate binary vector to obtain in-frame green fluorescent protein (GFP) fusions downstream of a 35S promoter. Golden Gate compatible overhangs and amino acids introduced are indicated. C, Golden Gate vectors were inserted in Agrobacterium tumefaciens. Twenty protein fusions were successfully expressed in Nicotiana benthamiana leaves by agroinfiltration. D, The subcellular localization of the fusions in leaf pavement cells was determined by live-cell imaging with a laser-scanning confocal microscope. The illustration is an overlay image of a free GFP (green) diffusing in the cytosol (c) and the nucleoplasm (n). nu: nucleolus, blue: chlorophyll (chloroplasts). E, Interaction with plant protein complexes was determined by anti-GFP coimmunoprecipitation (coIP) coupled with liquid chromatography-tandem mass spectrometry, abbreviated coIP/MS in the manuscript. F, A poplar homolog of a protein identified by coIP/MS was cloned and coexpressed with its cognate candidate effector to check their accumulation in the same compartments and their association within the same protein complex. 
specific and associated with only one candidate effector. In contrast, 158 (25\% of the dataset) proteins were promiscuous and coimmunoprecipitated with five or more candidate effectors and are unlikely to be genuine interactors. All the fusion proteins could be detected after coIP by either SDS-PAGE Coomassie blue staining, mass spectrometry, or both, indicating effective expression and immunoprecipitation (Supplementary Fig. S5). Biological replicates of the coIP/MS performed with four candidate effectors yielded overlapping sets of proteins, therefore validating the robustness of the approach (Supplementary Tables S3 and S4). We conclude that candidate effectors associate in planta with numerous plant proteins with a highly variable degree of specificity.

To further discriminate and classify the candidate effector interactors, we developed a scoring method based on specificity and peptide count. A high score reflects a higher likelihood for a plant protein to be a specific interactor and a reliable match (Fig. 5; Supplementary Fig. S6). Interactor protein scores varied from 0.01 to 45 , with an average value of 1.49 . All but one of the 29 proteins that yielded a score $\geq 5$ associated with one specific candidate effector and were robustly identified by mass spectometry with at least five peptides. Five candidate effectors associated with at least one plant protein with a score $\geq 5$ (Table 1; Fig. 6 ). For instance, the three proteins with the highest score were TOPLESS-related proteins and exclusively immunoprecipitated with MLP124017 (Figs. 5 and 6). Also, MLP105684 associated with several high-scoring myosins and annexins, whereas the chloroplast-resident candidate effector MLP124111 specifically associated with a chloroplastic coproporphyrinogen-III oxidase. All the high-scoring (score $\geq 5$ ) proteins have homologs in the predicted proteome of Populus trichocarpa (Fig. 6). Given their relative specificity, convincing peptide coverage, and similarity to poplar proteins, we view these interactors as the most likely to be biologically relevant. On the other hand, the low-scoring, promiscuous interactors are likely to include immunoprecipitation false positives (either highly abundant, sticky, or both) or proteins that associate with heterologously expressed proteins (e.g., translation machinery, unfolded protein response). Promiscuous plant proteins in these categories include many rubisco and photosystem subunits, chlorophyll-binding proteins, and heat shock cognate $70 \mathrm{kDa}$ proteins (Figs. 5 and 6).

\section{The candidate effector MLP124017 associates with the poplar TOPLESS-related protein 4 (PopTPR4) in planta.}

The interactor with the highest score that was revealed by coIP/MS is the $N$. benthamiana TOPLESS-related protein 4 (NbTPR4; score: 45), which associates with MLP124017 (Fig. 5). NbTPR4 shows $80 \%$ similarity (amino acid identity) to the poplar TPR4 (PopTPR4) (Supplementary Fig. S7). To test whether PopTPR4 physically interacts with MLP124017 in planta, we coexpressed a PopTPR4-mCherry fusion together with MLP124017-GFP in N. benthamiana leaf cells. The coIP experiments revealed that MLP124017-GFP and PopTPR4mCherry associate within the same protein complex in planta

Table 1. Melampsora larici-populina candidate effectors investigated in this study

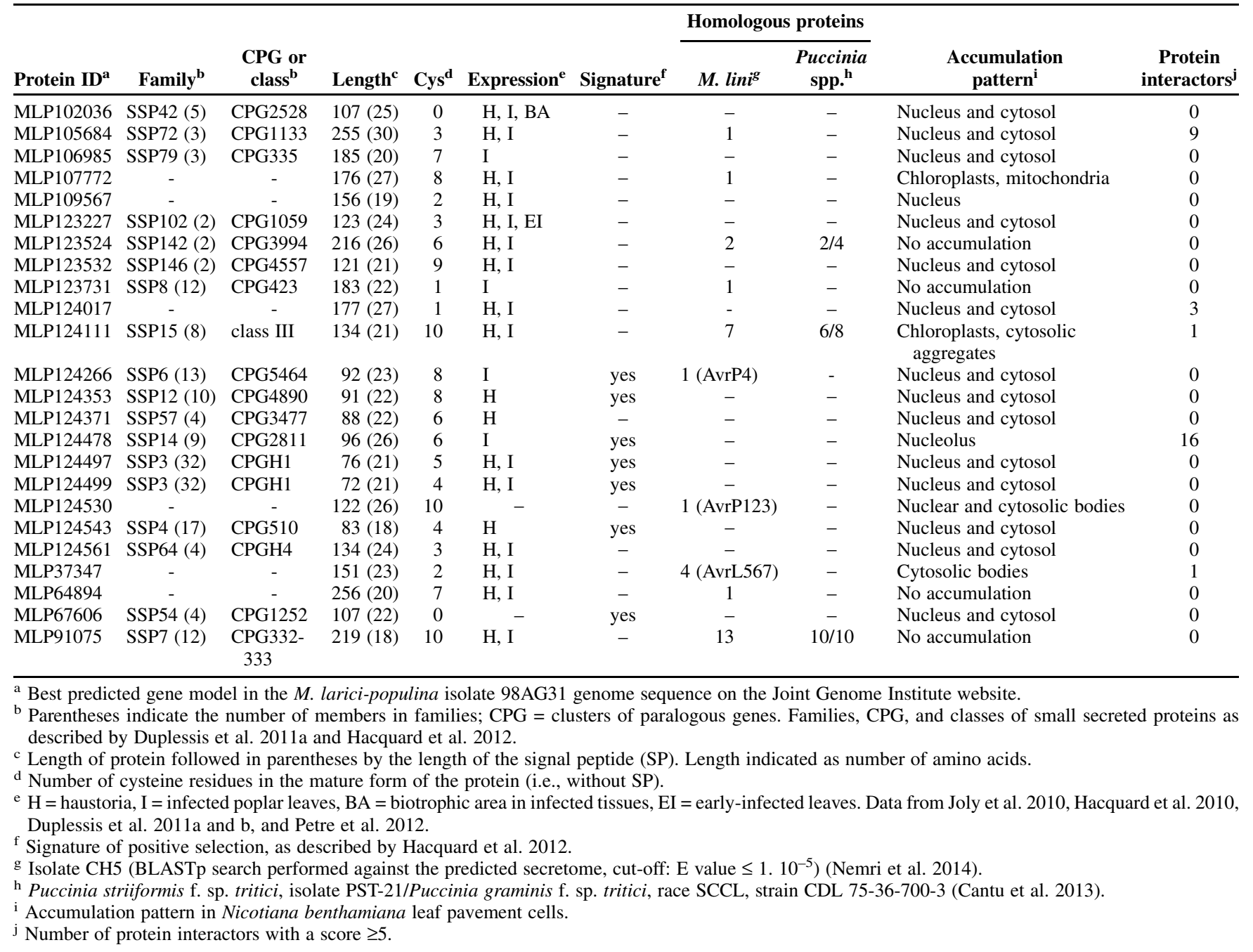


(Fig. 7A). None of the control proteins we used were able to immunoprecipitate with PopTPR4 (free GFP, MLP105684-GFP) or MLP124017-GFP (nuclear mCherry), indicating that the association between MLP124017 and PopTPR4 is specific. Confocal microscopy showed that PopTPR4-mCherry accumulates in the nucleus of $N$. benthamiana leaf cells, whereas MLP124017-GFP accumulates both in the nucleus and the cytosol, as observed earlier (Figs. $2 \mathrm{H}$ and $7 \mathrm{~B}$ ). We conclude that PopTPR4 and MLP124017 specifically interact in planta, and that this association probably happens in the nucleus.

\section{DISCUSSION}

In this study, we took advantage of the availability of the genome sequence of the rust pathogen $M$. larici-populina to select the most promising candidates among the large predicted effector complement. We used an in planta effectoromics pipeline that combines cellular localization and proteomics-based protein-protein interaction screens to validate effector proteins. Our findings indicate that $M$. larici-populina probably manipulates plant cells by deploying effector proteins that target multiple compartments and processes. Our study also supports the view that heterologous plants can provide useful systems for effectoromics of obligate biotrophs such as rust fungi.

Eight out of the 20 tested candidate effectors yielded informative findings when expressed in plant cells: three
(MLP124530, MLP109567, and MLP107772) showed a specific localization, two (MLP124017 and MLP105684) associated with a high-scoring partner, and three (MLP124478, MLP124111, and MLP3747) showed both a specific localization and a high-scoring partner (Table 1). Direct demonstration of effector entry into host cells remains technically challenging for filamentous plant pathogens (Petre and Kamoun 2014). Therefore, heterologous expression in plant cells is viewed as an alternative approach to study effectors. Candidates that yield a particular phenotype, localize to a particular host cell compartment, or display specific interaction with plant proteins are more likely to be genuine cytoplasmic effectors. Therefore, we conclude that the eight above-mentioned proteins are probable bona fide host-translocated effectors. Noteworthy, we did not find any common features within these proteins, either in the $\mathrm{N}$-terminus or in the entire protein sequence, suggesting that the primary structure of any potential host-cell targeting sequence is not conserved.

Twelve of the candidate effectors we tested yielded neither a specific cellular localization nor a high-scoring plant interactor (Table 1). Two main factors may account for this absence of informative results. First, the selection pipeline we used may have yielded false positives, i.e., secreted proteins that do not function as translocated effectors. Indeed, unlike oomycete cytoplasmic effectors, which can be readily identified from secretome databases based on the presence of diagnostic motifs

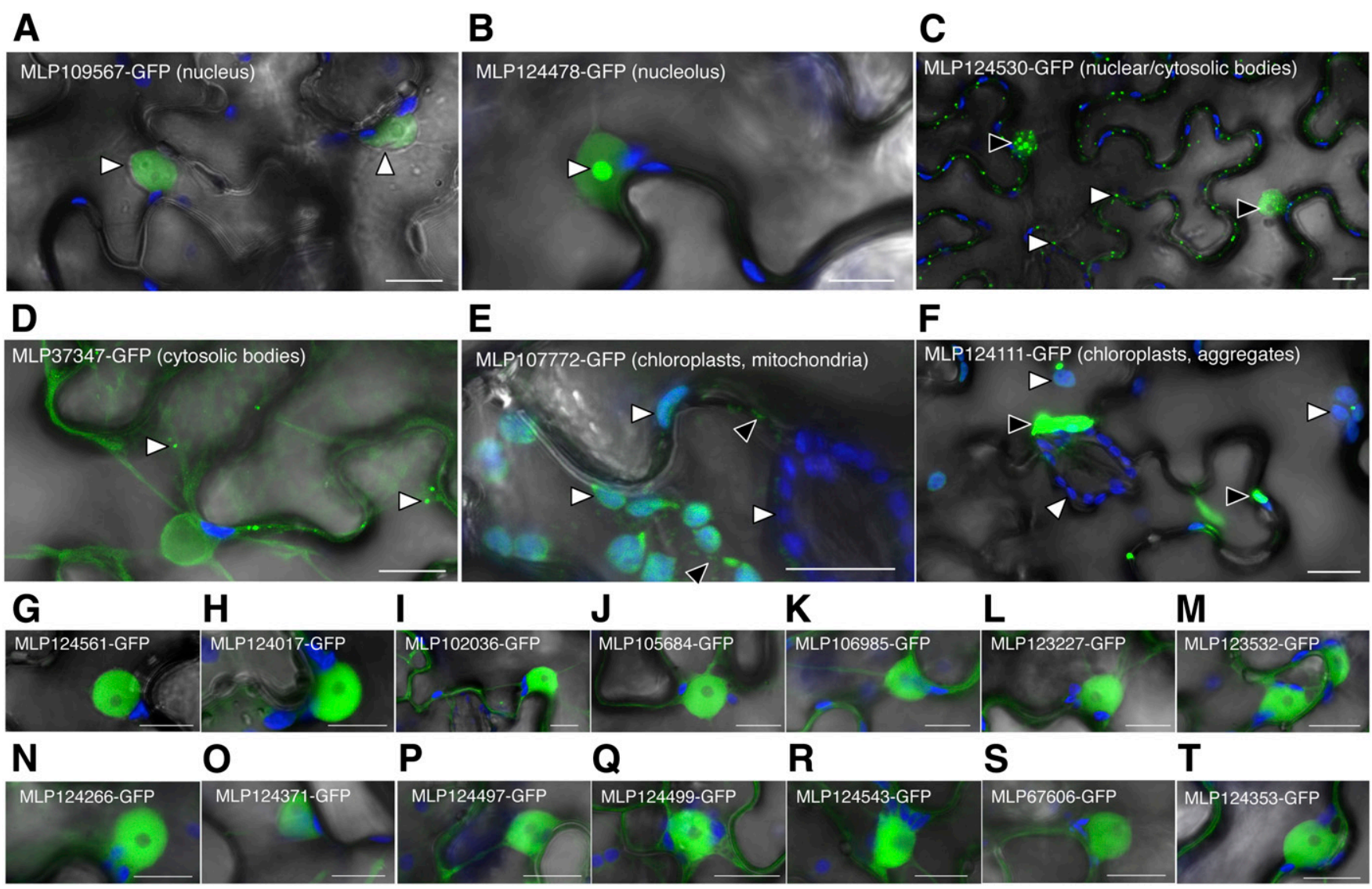

Fig. 2. Candidate effectors accumulate in distinct subcellular compartments. A to $\mathbf{F}$, Representative images corresponding to the six fusion proteins accumulating in the distinct subcellular compartments indicated in parentheses. White arrowheads indicate nuclei (MLP109567), the nucleolus (MLP124478), small cytosolic bodies (MLP124530, MLP37347), and chloroplasts (MLP107772, MLP124111). Black arrowheads indicate nuclear bodies (MLP124530), mitochondria (MLP107772), and large cytosolic aggregates (MLP124111). G to T, Representative images corresponding to the 14 fusion proteins accumulating in the nucleoplasm and the cytosol. The fusion proteins were transiently expressed in Nicotiana benthamiana leaf cells by agroinfiltration. Live-cell imaging was performed with a laser-scanning confocal microscope 2 days after infiltration. The green fluorescent protein (GFP) and the chlorophyll were excited at $488 \mathrm{~nm}$. GFP (green) and chlorophyll (blue) fluorescence was collected at 505 to $525 \mathrm{~nm}$ and 680 to $700 \mathrm{~nm}$, respectively. Images present single optical sections of $0.8 \mu \mathrm{m}$ or maximal projection of up to 15 optical sections (maximum z-stack of $12 \mu \mathrm{m}$ ). Images displayed are overlays of the GFP signal, the chlorophyll signal, and bright field. Scale bars: $10 \mu \mathrm{m}$. 
such as RXLR and LXLFLAK (Haas et al. 2009; Raffaele et al. 2010; Whisson et al. 2007), the identification of translocated effectors in fungi is more problematic (Cantu et al. 2013; Hacquard et al. 2012; Petre and Kamoun 2014; Saunders et al. 2012). In the rust fungi, haustorial-expression has been used to predict host-translocated effectors (Catanzariti et al. 2006; Kemen et al. 2005). Our candidate list was enriched in genes expressed in haustoria. However, the interface between haustoria and host cells is a complex compartment and some of the secreted proteins that are expressed at that interface may not be cytoplasmic effectors (Kemen et al. 2013; Rafiqi et al. 2012). Second, our in silico pipeline may have revealed genuine effectors that could not be validated experimentally, due to the limitations of using a heterologous system. For instance, the lack of specific association between many candidate effectors and $N$. benthamiana proteins could result from target diversification, with the poplar being too divergent from any $N$. benthamiana homologs. Indeed, effector proteins from parasites with a narrow host range can be specialized to proteins from their natural hosts (Dong et al. 2014; Win et al. 2012). Also, many host-translocated effectors function in one or both the cytosol or the nucleus of host cells (Win et al. 2012). Our cell biology screen would not have revealed such effectors, since this pattern of accumulation is noninformative because it is similar to the free GFP control.

M. larici-populina candidate effectors localized specifically to plant nuclei, nucleoli, chloroplasts, and mitochondria (Fig. 2). Several effectors of fungi and oomycetes have been previously reported to localize to host nuclear compartments (Caillaud et al. 2012; Schornack et al. 2010; Stam et al. 2013), a seemingly important host cellular compartment for interactions between filamentous pathogens and plants. In contrast, localization of MLP107772 to chloroplasts and mitochondria is a novel finding for filamentous plant pathogen effectors. To date, only bacterial effectors have been linked to these organelles (Block et al. 2010; Jelenska et al. 2007; Li et al. 2014; Rodríguez-Herva et al. 2012). Accumulation of MLP107772 in

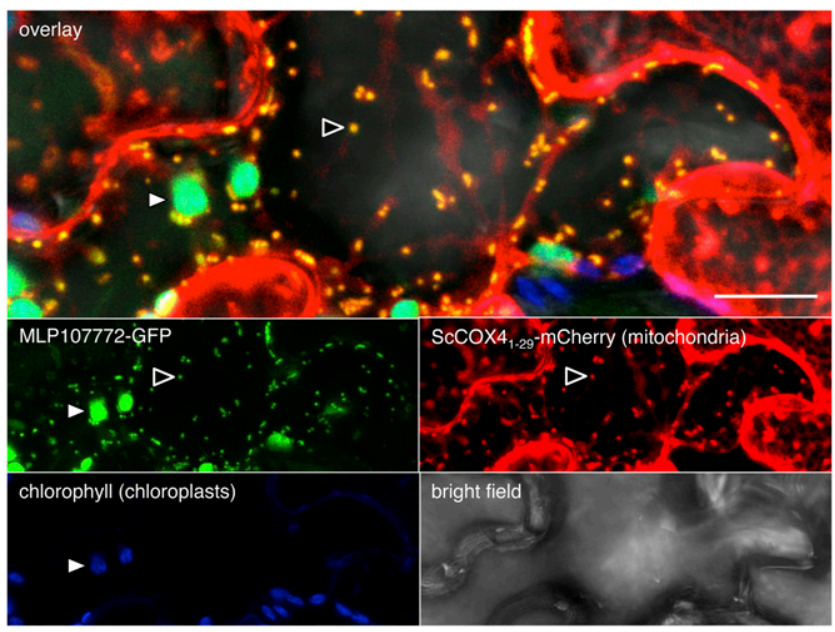

Fig. 3. MLP107772-green fluorescent protein (GFP) accumulates in chloroplasts and mitochondria. Live-cell imaging of MLP107772-GFP and ScCOX4 ${ }_{1-29^{-}}$ mCherry (mitochondria marker) in Nicotiana benthamiana leaf pavement cells. Proteins were transiently coexpressed in $N$. benthamiana leaf cells by agroinfiltration. Live-cell imaging was performed with a laser-scanning confocal microscope in a sequential scanning mode 2 days after infiltration. The GFP and the chlorophyll were excited at $488 \mathrm{~nm}$; the mCherry was excited at $561 \mathrm{~nm}$. GFP (green), mCherry (red), and chlorophyll (blue) fluorescence was collected at 505 to $525 \mathrm{~nm}, 580$ to $620 \mathrm{~nm}$, and 680 to $700 \mathrm{~nm}$, respectively. Images present a maximal projection of 12 optical sections (z-stack: $9.6 \mu \mathrm{m}$ ). Black arrowheads indicate overlapping GFP and mCherry signals in mitochondria. White arrowheads indicate overlapping GFP and chlorophyll signals in chloroplasts. Scale bar: $10 \mu \mathrm{m}$.

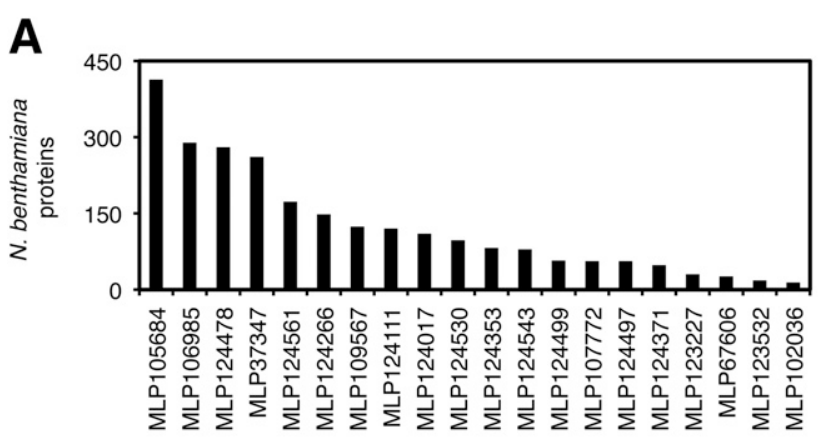

B

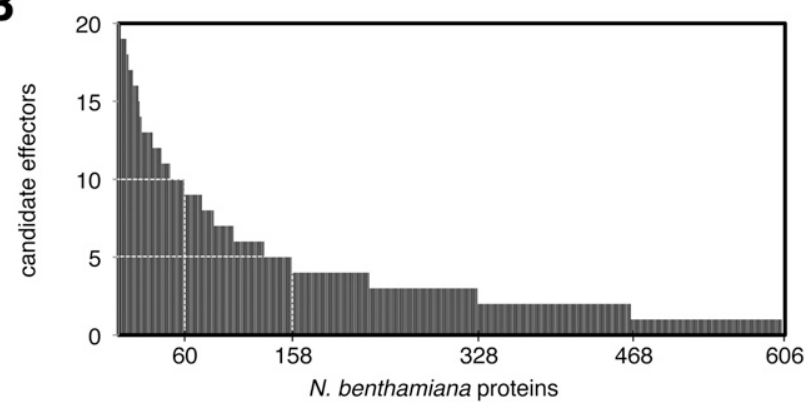

Fig. 4. Candidate effectors associate with 606 Nicotiana benthamiana proteins. A, Number of $N$. benthamiana proteins associated with each individual candidate effector. The 20 candidate effectors are sorted from left to right in descending order, according to the number of interactors identified by coimmunoprecipitation (coIP) coupled with liquid chromatography-tandem mass spectrometry (LC-MS/MS). B, Number of candidate effectors associated with each individual $N$. benthamiana protein. The 606 interactors are sorted from left to right in descending order, according to the number of candidate effectors they associated with. The $x$ axis legend indicates (from right to left) the number of $N$. benthamiana proteins associated with at least one (606), two (468), three (328), five (158), and ten (60) candidate effectors. Proteins were transiently expressed in $N$. benthamiana leaf cells by agroinfiltration. Proteins were isolated 2 days after infiltration. Plant protein complexes associated with the candidate effector-green fluorescent protein (GFP) fusions were purified by anti-GFP coIP, were separated by $15 \%$ sodium dodecyl sulfate-polyacrylamide gel electrophoresis, and were digested with trypsin. Tryptic peptides were processed by LC-MS/MS and collected peaks were used to search a database containing the predicted proteome of $N$. benthamiana. After filtering contaminants and clustering similar $N$. benthamiana proteins, a total of 606 nonredundant proteins were retained.

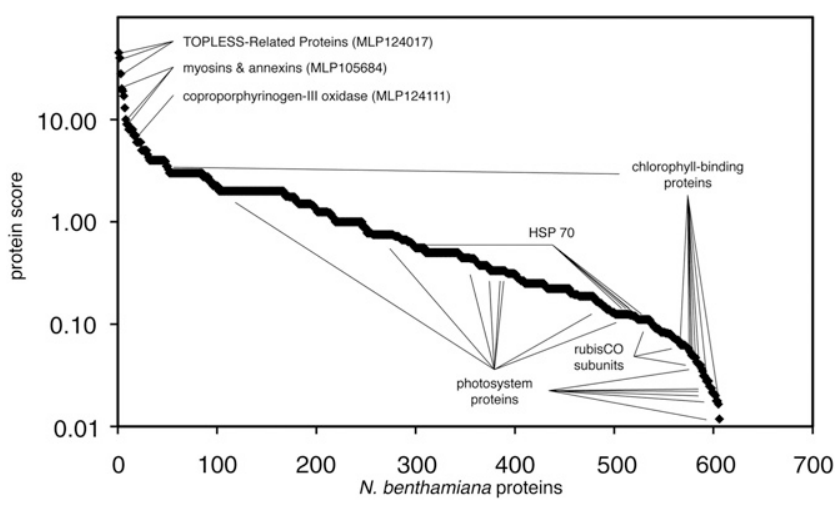

Fig. 5. A scoring system allows discriminating between redundant and specific interactors. For each Nicotiana benthamiana protein identified by coimmunoprecipitation followed by liquid chromatography-tandem mass spectrometry, a score was calculated as follows: protein score = maximal peptide count divided by (redundancy) ${ }^{2}$. Proteins are sorted from left to right in descending scores, representing the gradient of likelihood of being a biologically relevant interactor. Selected proteins are indicated on the graph. 
both chloroplasts and mitochondria is reminiscent of the dual targeting of numerous plant proteins to these organelles (Carrie et al. 2009). We noted that MLP107772 carries a predicted transit peptide of 83 amino acids (ChloroP 1.1 score: 0.533; cs-score: 1.040) immediately following its signal peptide. Transit peptides are typically cleaved by processing peptidases after translocation into the organelles (Teixeira and Glaser 2013). Accordingly, immunoblots showed a band $8 \mathrm{kDa}$ smaller than expected for MLP107772-GFP, suggesting in planta processing. We also noted that the $N$. benthamiana chloroplastic presequence protease 1 (Protein ID NICBE_142969.1_TGAC), a protein involved in chloroplast transit peptide processing, associated with MLP107772-GFP in coIP experiments.

The coIP screen revealed a potential in planta interactome of 606 plant proteins for the $20 \mathrm{M}$. larici-populina candidate effectors. In total, $74 \%$ of the identified proteins associated with more than one of the tested candidate effectors, and $25 \%$ with more than five, suggesting a high rate of promiscuity. These promiscuous proteins are most probably enriched in false positives, whereas the more specific interactors are more likely to be biologically relevant. Affinity purification-mass spectrometry approaches often yield overlapping sets of false positives, notably highly abundant and sticky proteins (Mellacheruvu et al. 2013). In addition, proteins expressed in vivo, as in our case, could be expected to yield additional false positives related to the translation machinery and unfolded protein response. Scoring or indexing systems can be used to highlight the most relevant fraction of the interactome (Miteva et al. 2013). We developed a scoring system that helped to flag interactors that are more likely to be biologically relevant and worthy of further investigation (Figs. 5 and 6). In addition, this index highlights a list of usual suspects of coIP assays in $N$. benthamiana, which should prove useful for the community. Nonetheless, it is difficult to draw a sharp line between such usual suspects and biologically relevant interactors. An alternative hypothesis to explain the redundancy is that $M$. laricipopulina effectors have evolved to converge on the same target proteins in plant cells, as reported for other pathogen effectors (Mukhtar et al. 2011; Song et al. 2009; Weßling et al. 2014). However, given the relatively high noise rate in protein-protein interaction assays, it is challenging to distinguish such effector "hubs" from false positives.

MLP124017 specifically associates with $N$. benthamiana and poplar TOPLESS and TOPLESS-related proteins (TPL/TPR) (Figs. 6 and 7). TPL/TPR were not detected across multiple coIP/MS experiments in $N$. benthamiana, which reinforces the specificity of their association with MLP124017. TPL/TPR are transcriptional corepressors involved in a wide range of processes including plant immune responses (Causier et al. 2012). For instance, A. thaliana JAZ proteins recruit TPL/TPR to repress jasmonate signaling (Pauwels et al. 2010). The biological

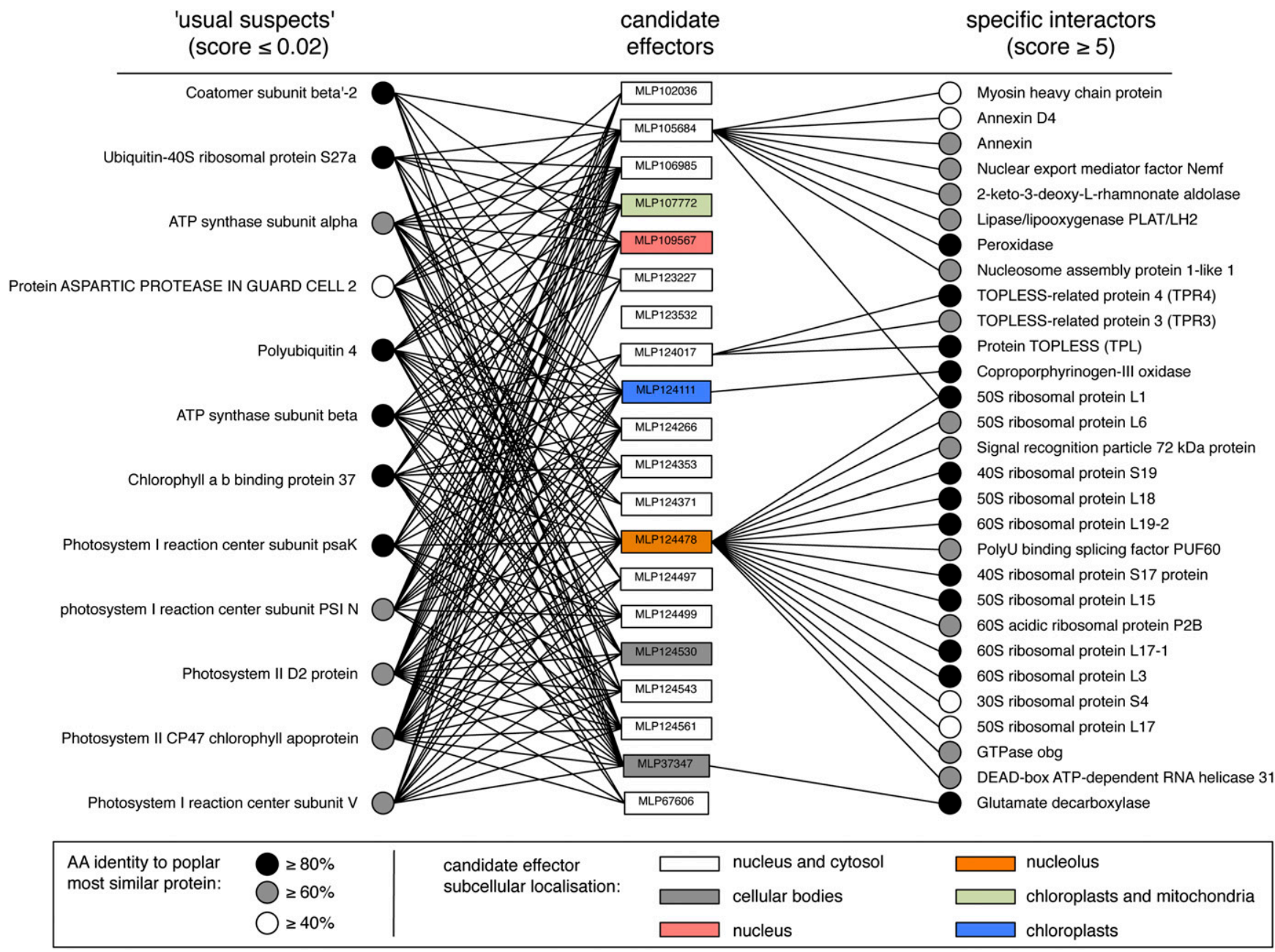

Fig. 6. Interactome network with selected low and high-scoring interactors. The 12 plant proteins with the lowest scores ( $\leq 0.02$; called usual suspects) and the 29 plant proteins with the highest scores ( $\geq 5$; called specific interactors) are shown on the left- and right-hand sides, respectively. Black lines indicate the association with a candidate effector as detected by coimmunoprecipitation followed by liquid chromatography-tandem mass spectrometry. The closest poplar homologs were identified by protein sequence homology searches against the predicted proteome of Populus trichocarpa v3, using the BLASTp algorithm. 
significance of the association between MLP124017 and PopTPR4 will be investigated in the future.

\section{MATERIALS AND METHODS}

Biological materials and growth conditions.

Escherichia coli (subcloning efficiency DH5 $\alpha$ competent cells; Invitrogen, Carlsbad, CA, U.S.A.) and Agrobacterium tumefaciens (electrocompetent strain GV3101) were conserved at $-80^{\circ} \mathrm{C}$ and were grown in $\mathrm{L}$ medium at 37 and $28^{\circ} \mathrm{C}$, respectively. $N$. benthamiana plants were grown in greenhouses at $22^{\circ} \mathrm{C}$ under 16 -h day and 8 -h night conditions.

\section{In silico sequence analyses.}

Predicted protein sequences were retrieved as follows: M. larici-populina isolate 98AG31 (Joint Genome Institute Genome portal) (Duplessis et al. 2011a), M. lini isolate CH5 (Nemri et al. 2014), N. benthamiana (Sol Genomics Network) (Bombarely et al. 2012), and P. trichocarpa (Phytozome P. trichocarpa website) (Tuskan et al. 2006). Protein sequence analysis was performed with ClustalX and Jalview programs. Transit peptides were predicted with ChloroP 1.1. BlastP searches were performed with the BLAST+ program, using the predicted $P$. trichocarpa proteome v3.0 (Tuskan et al. 2006) or the predicted secretome of M. lini (Nemri et al. 2014) as databases. The set of candidate effectors selected via the pipeline was manually analyzed to remove redundant family members; the family member showing the highest gene expression during poplar leaf infection was conserved. MLP124497 and MLP124499, two divergent members of the small secreted protein family 3 , were both highly expressed in planta and, thus, were both retained (Duplessis et al. 2011a; Hacquard et al. 2012).

\section{Cloning procedures and plasmids.}

The open reading frame (ORF) coding the mature form (i.e., without the signal peptide) of M. larici-populina small secreted proteins or coding the full length to poplar TPR4 were amplified by polymerase chain reaction (PCR) using cDNA from Beaupré leaves infected by $M$. larici-populina (isolate 98AG31) (Petre et al. 2012) or were obtained through gene synthesis (Genewiz, London) with codon optimization for plant expression and removal of internal $B b s I$ and $B s a \mathrm{I}$ restriction sites. Primers and synthetic genes were designed to generate BbsI AATG/ggTTCG-compatible overhangs to be compatible with the suite of Golden Gate vectors. For cloning and sequencing purpose, DNA fragments were inserted into the Golden Gate level 0 vector pICSL01005 (BbsI-compatible overhangs AATG/ggTTCG) following a digestion and ligation procedure (Weber et al. 2011) (SynBio@TSL website). Sequences of DNA fragments obtained by PCR were verified by sequencing (GATC Biotech, Constance, Germany). To generate $\mathrm{C}$-terminally tagged proteins, the ORF of the protein of interest (BsaI-compatible overhangs AATG/ggTTCG) was
A
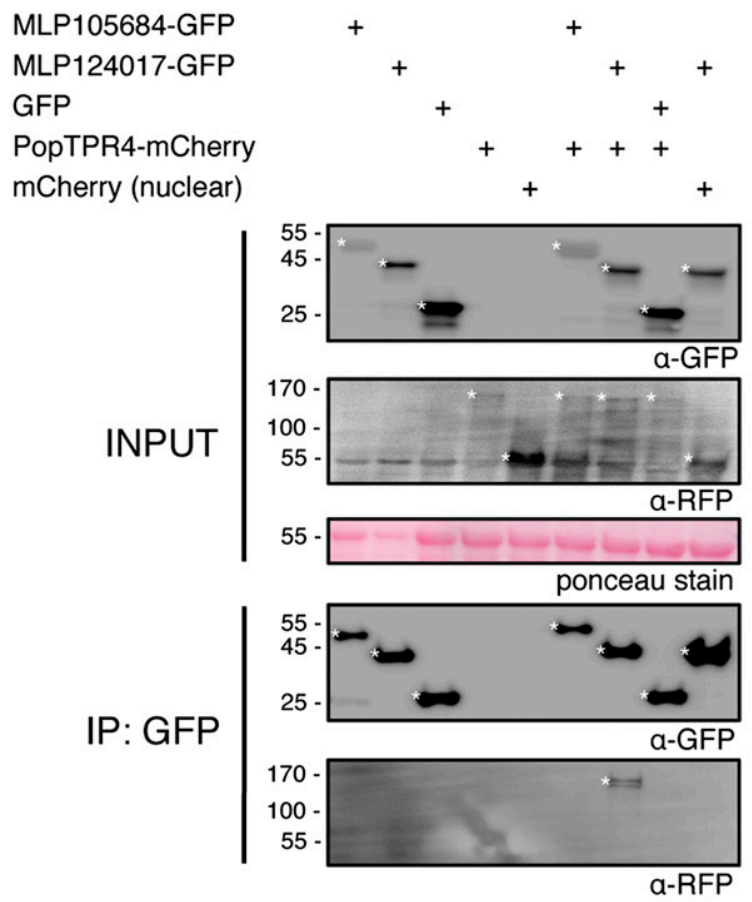

B

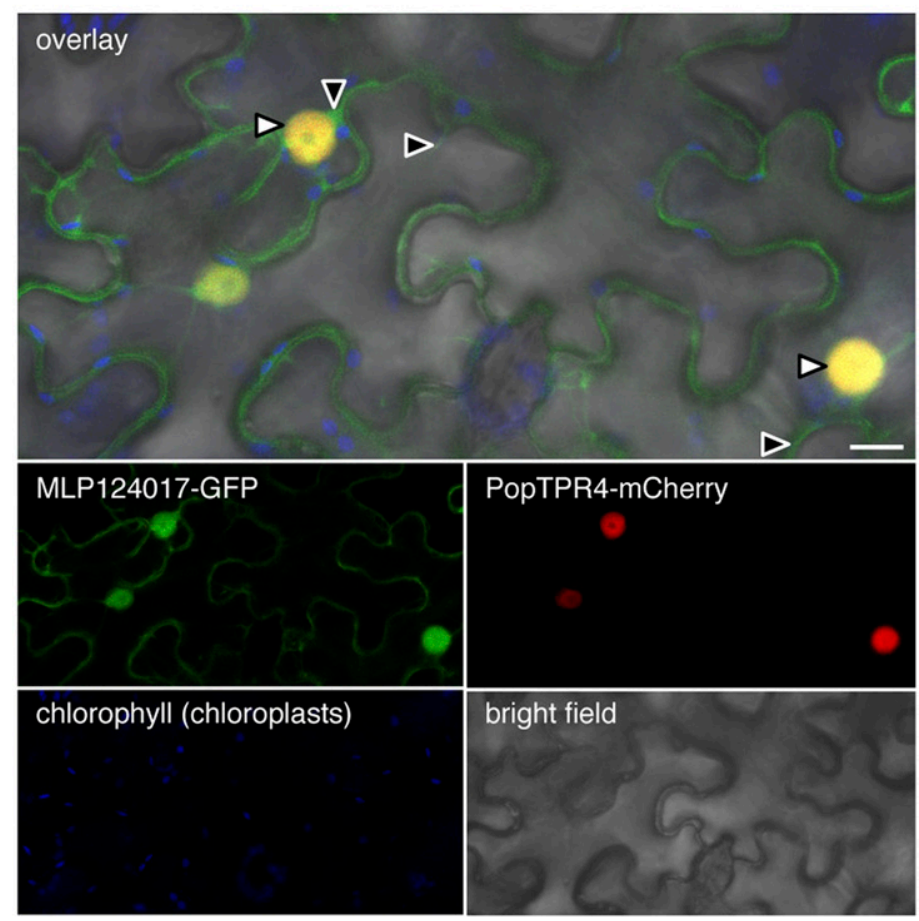

Fig. 7. MLP124017 associates with the TOPLESS-related protein 4 (PopTPR4) from poplar. A, Immunoblots performed with immunoprecipitated protein mixtures. Proteins were isolated from agroinfiltrated leaves and were immediately used for anti-green fluorescent protein (GFP) or anti-red fluorescent protein (RFP) immunoprecipitation (IP). Immunoprecipitated protein mixtures were separated by $12 \%$ sodium dodecyl sulfate-polyacrylamide gel electrophoresis and were electrotransfered onto polyvinylidene diflouride (PVDF) membranes. Immunodetection was performed with anti-GFP or anti-RFP antibodies, and immunoblots were revealed with a chemiluminescent imager. Ponceau staining of the PVDF membrane was used as a loading control. Asterisks indicate specific protein bands. Numbers on the left side of the blots indicate protein size in kilodaltons. B, Live-cell imaging of MLP124017-GFP and PopTPR4mCherry in $N$. benthamiana leaf pavement cells. Live-cell imaging was performed with a laser-scanning confocal microscope in a sequential scanning mode. The GFP and the chlorophyll were excited at $488 \mathrm{~nm}$; the mCherry was excited at $561 \mathrm{~nm}$. GFP (green), mCherry (red), and chlorophyll (blue) fluorescence was collected at 505 to $525 \mathrm{~nm}, 580$ to $620 \mathrm{~nm}$, and 680 to $700 \mathrm{~nm}$, respectively. Images show a single optical section. White arrowheads indicate overlapping GFP and mCherry signals in the nuclei. Black arrowheads indicate GFP signal in the cytosol. Scale bar: $10 \mu \mathrm{m}$. Proteins were transiently expressed in $N$. benthamiana leaf cells by agroinfiltration. Leaves were harvested 2 days after infiltration and were immediately used for protein isolation (A) or live-cell imaging (B). 
assembled with the ORF of a GFP or a mCherry (BsaIcompatible overhangs ggTTCG/GCTT) into the Golden Gate level 1 binary vector pICH86988 (BsaI-compatible overhangs AATG/GCTT; 35S promoter/ octopine synthase terminator). Plasmids were multiplied using $E$. coli. Level 1 vectors were inserted in A. tumefaciens GV3101, and transformed bacteria were conserved at $-80^{\circ} \mathrm{C}$ in $20 \%$ glycerol for further use (Fig. 1).

Transient protein expression in $N$. benthamiana leaf cells.

A. tumefaciens GV3101 was used to deliver T-DNA constructs into leaf cells of 3-week-old $N$. benthamiana plants, following the agroinfiltration method previously described (Win et al. 2011). Briefly, overnight-grown bacterial cultures were adjusted to an optical density at $600 \mathrm{~nm}\left(\mathrm{OD}_{600}\right)$ of 0.2 into an infiltration buffer $(10 \mathrm{mM} \mathrm{MgCl} 2,150 \mu \mathrm{M}$ acetosyringone) $1 \mathrm{~h}$ before leaf infiltration. For all cotransformations, A. tumefaciens strains were mixed in a 1:1 ratio in infiltration buffer to a final $\mathrm{OD}_{600}$ of 0.2 . The leaves were collected 2 days after infiltration for further protein isolation or microscopy.

\section{Live-cell imaging by laser-scanning confocal microscopy.}

Small pieces of leaves were mounted in water between a slide and a coverslip (inferior face toward the objective) and were immediately observed. Live-cell imaging was performed with a Leica DM6000B/TCS SP5 laser-scanning confocal microscope (Leica Microsystems, Bucks, U.K.), using 10× (air), $40 \times$ (air), and $63 \times$ (water immersion) objectives. The GFP and the chlorophyll were excited at $488 \mathrm{~nm}$, whereas the mCherry was excited at $561 \mathrm{~nm}$. Specific emission signals corresponding to the GFP, the mCherry, and the chlorophyll were collected between 505 to $525 \mathrm{~nm}, 580$ and $620 \mathrm{~nm}$, and 680 and $700 \mathrm{~nm}$, respectively. Scanning was performed in sequential mode when needed. Each construct gave a similar localization pattern across at least three independent observations. Image analysis was performed with Fiji. After observation, leaves were frozen in liquid nitrogen and were conserved at $-80^{\circ} \mathrm{C}$ for further use.

\section{Total protein isolation.}

$N$. benthamiana leaves were harvested 2 days after infiltration, were frozen in liquid nitrogen, and were ground into powder with mortar and pestle. Total protein extraction was performed by reducing and denaturing proteins from the leaf powder $10 \mathrm{~min}$ at $95^{\circ} \mathrm{C}$ in a Laemmli buffer $(0.5 \mathrm{M}$ Tris- $\mathrm{HCl}, \mathrm{pH} 6.8,10 \mathrm{mM}$ dithiothreitol [DTT], 2\% SDS, $20 \%$ glycerol) in order to avoid in vitro nonspecific degradation of the fusion proteins. Then, $10 \mu \mathrm{l}$ of isolated proteins were separated by $15 \%$ SDS-PAGE, and the protein content was estimated by Coomassie blue staining.

\section{Immunoblot analyses.}

Immunoblots aimed at checking the integrity of the fusion proteins present in total extracts were performed as described by Pégeot et al. 2014. For immunoblots aimed at detecting fusion proteins after coIP, proteins were separated by SDSPAGE and were electrotransferred onto a polyvinylidene diflouride membrane using a Trans-Blot turbo transfer system (Bio-Rad, Munich). The membrane was blocked with $3 \%$ bovine serum albumin (BSA) in Tris-buffered saline and Tween 20. GFP detection was performed in a single step by a GFP (B2):sc-9996 horseradish peroxidase (HRP)-conjugated antibody (Santa Cruz Biotechnology, Santa Cruz, CA, U.S.A.); mCherry detection was performed with a rat anti-RFP (red fluorescent protein) 5F8 antibody (Chromotek, Munich) and a HRP-conjugated antirat antibody. Membrane revelation was carried out with an ImageQuant LAS 4000 luminescent imager (GE Healthcare Life Sciences, Piscataway, NJ, U.S.A.). Ponceau staining of the rubisco was used as a loading control.
Purification of GFP fusions-protein complexes by coIP.

The coIP protocol described by Win and colleagues (2011) was adapted for GFP and RFP fusions with the following modifications. To maximize the recovery of organelle proteins, leaf mixtures were sonicated for $10 \mathrm{~min}$ in an ice-cold water bath prior to protein isolation. Immunoprecipitation was performed by affinity chromatrography with GFP or RFP_Trap_A beads (Chromotek), and elution of the proteins from the beads was performed by heating $10 \mathrm{~min}$. at $70^{\circ} \mathrm{C}$.

\section{Sample preparation for mass spectrometry.}

Samples for liquid chromatography/tandem mass spectrometry (LC-MS/MS) analysis were prepared by excising bands from one-dimensional SDS-PAGE gels stained with Instant Blue (Expedeon, Cambridge). The gel slices were destained in $50 \%$ acetonitrile (ACN), and cysteine residues modified by a $30-$ min reduction in $10 \mathrm{mM}$ DTT, followed by a $30-\mathrm{min}$ alkylation with $55 \mathrm{mM}$ iodoacetamide. All the above-mentioned solutions used $50 \mathrm{mM}$ ammonium bicarbonate (ABC) as a buffer. After extensive washing with destaining solution (50:50 [vol/vol] ACN and $50 \mathrm{mM} \mathrm{ABC)} \mathrm{and} \mathrm{100 \%} \mathrm{ACN,} \mathrm{gel}$ pieces were incubated with trypsin (Promega, Charbonnières, France) in $50 \mathrm{mM} \mathrm{ABC}$ and $5 \% \mathrm{ACN}$ in water at $37^{\circ} \mathrm{C}$ overnight. Peptides were recovered by triple extraction with $5 \%$ formic acid (FA) and $50 \% \mathrm{ACN}$, were evaporated to dryness, and were dissolved in $2 \% \mathrm{ACN}, 0.1 \%$ trifluoroacetic acid.

\section{LC-MS/MS analysis.}

LC-MS/MS analysis was performed using a hybrid mass spectrometer LTQ-Orbitrap XL (ThermoFisher Scientific, Waltham, MA, U.S.A.) and a nanoflow-ultra-high performance liquid chromatography system (nanoAcquity; Waters Corp.) The peptides were applied to reverse phase trap column (Symmetry C18, $5 \mu \mathrm{m}, 180 \mu \mathrm{m} \times 20 \mathrm{~mm}$; Waters Corp., Milford, MA, U.S.A.) connected to an analytical column (BEH 130 $\mathrm{C} 18,1.7 \mu \mathrm{m}, 75 \mu \mathrm{m} \times 250 \mathrm{~mm}$; Waters Corp.) in vented configuration using nano-T coupling union in $0.1 \% \mathrm{ACN}$ in $0.1 \%$ FA (solvent B). Peptides were eluted in a gradient of 3 to $40 \%$ of solvent $\mathrm{B}$ of acid over $50 \mathrm{~min}$, followed by gradient of 40 to $60 \%$ of solvent B over $3 \mathrm{~min}$ at a flow rate of $250 \mathrm{nl}$ per minute at $40^{\circ} \mathrm{C}$. The mass spectrometer was operated in positive ion mode with nano-electrospray ion source with ID $0.02 \mathrm{~mm}$ fused silica emitter (New Objective; Scientific Instrument Services, Inc., Ringoes, NJ, U.S.A.). Voltage $+2 \mathrm{kV}$ was applied via platinum wire held in a PEEK T-shaped coupling union. Transfer capillary temperature was set to $200^{\circ} \mathrm{C}$, no sheath gas, and the focusing voltages in factory default setting were used. The Orbitrap full mass scan with 60,000 resolution at $400 \mathrm{~m} / \mathrm{z}$, range 300 to $2,000 \mathrm{~m} / \mathrm{z}$ was used, automatic gain control (AGC) target set to $1,000,000$ counts, and maximum inject time to $1,000 \mathrm{~ms}$. In the linear ion trap, MS/MS spectra were triggered with data-dependent acquisition method for the five most intense ions. The threshold for triggering collision induced dissociation (CID) was 1,000 counts, normal scan rate, AGC accumulation target was set to 30,000 counts, and maximum inject time to $150 \mathrm{~ms}$. A data-dependent algorithm was used to collect as many tandem spectra as possible from all masses detected in master scan in the Orbitrap analyzer. Orbitrap prescan functionality, isolation width $2 \mathrm{~m} / \mathrm{z}$, and collision energy set to $35 \%$ were used. The selected ions were then fragmented in the ion trap using CID. Dynamic exclusion was enabled, allowing for one repeat, $60 \mathrm{~s}$, and $\mathrm{m} / \mathrm{z}$ window $\pm 10 \mathrm{ppm}$ from measured precursor masses, and with a maximal size of dynamic exclusion list of 500 items. Chromatography function to trigger a MS/MS event close to the peak summit was used with correlation set to 0.9 and expected peak width set to $7 \mathrm{~s}$. Charge state screening enabled allowed only charge states 
higher than $2+$ to be selected for MS/MS fragmentation. Monoisotopic mass recognition was on.

\section{LC-MS/MS data processing and peptide identification.}

Peak lists in format of Mascot generic files were prepared from raw data using Proteome Discoverer v1.2 (ThermoFisher Scientific) that (if required) were concatenated using in house-developed Perl script. Peak picking settings were as follows: $\mathrm{m} / \mathrm{z}$ range set to 300 to 5,000 , minimum number of peaks in a spectrum was set to $1, \mathrm{~S} / \mathrm{N}$ threshold for Orbitrap spectra was set to 1.5 , and automatic treatment of unrecognized charge states was used. Peak lists were searched on Mascot server v.2.4.1 (Matrix Science, Boston) against a Nicotiana benthamiana database with added constructs and typical proteomics contaminants such as keratins, trypsin, and others. Tryptic peptides only, up to two possible miscleavages and charge states $+2,+3,+4$, were allowed in the search. The modifications included in the search were oxidized methionine as variable modification and carbamidomethylated cysteine as static modification. Data were searched with a monoisotopic precursor and fragment ions mass tolerance of $10 \mathrm{ppm}$ and 0.8 Da respectively. Mascot results were combined in Scaffold v.4 (Proteome Software, Inc., Portland, OR, U.S.A.). Peptide identifications were accepted if they could be established at greater than $95.0 \%$ probability (false discovery rate $[\mathrm{FDR}]<$ 0.17 ) by the Peptide Prophet algorithm with Scaffold deltamass correction. Protein identifications were accepted if they could be established at greater than $99.0 \%$ probability (FDR < 0.1 ) and contained at least two identified peptides. Protein probabilities were assigned by the Protein Prophet algorithm. Proteins that contained similar peptides and could not be differentiated based on MS/MS analysis alone were grouped to satisfy the principles of parsimony (Searle 2010).

\section{Filtering and scoring of the M. larici-populina candidate effector interactome.}

LC-MS/MS data were used to generate a draft candidate effector interactome of $814 \mathrm{~N}$. benthamiana proteins. This list was filtered by removing non- $N$. benthamiana proteins (keratin, GFP, trypsin, BSA) and by clustering together $N$. benthamiana proteins sharing at least $80 \%$ amino acid identity over a minimum of $80 \%$ of the protein length, following a in-house bioinformatic pipeline based on the blastclust progamme (J. Win, S. Kamoun, and A. M. Jones, unpublished). This approach decreased the list to 632 $N$. benthamiana proteins. Finally, proteins supported by a single peptide in the dataset were discarded. The final candidate effector interactome consisted of 606 proteins and is presented in Supplementary Table S2. For each plant protein, a score was calculated according to the following formula: protein score $=$ maximal peptide count/(redundancy) ${ }^{2}$. The maximal peptide count is the highest number of peptides (total spectrum count method) identified with a single candidate effector-GFP fusion. Redundancy is the number of fusion proteins with which a given plant protein coimmunoprecipitated.

\section{ACKNOWLEDGMENTS}

We warmly thank H. Germain and colleagues (Université du Québec à Trois-Rivières, Canada) for fruitful and frequent discussions during the course of the study. We also thank D. Joly (Université de Moncton, Canada) and S. Hacquard (Max Planck Institute, Germany) for their help with the selection of M. larici-populina candidate effectors. We thank our colleagues at The Sainsbury Laboratory (TSL), the John Innes Centre (JIC), and The Genome Analysis Centre (TGAC; Norwich, U.K.) and at the Université de Lorraine and the Institute for Agronomy Research (INRA) (Nancy, France) for great discussions. We thank T. Buck for useful insights into the protein-protein interaction networks. B. Petre is supported by an INRA Contrat Jeune Scientifique, by the European Union, in the framework of the Marie-Curie FP7 COFUND People Programme, through the award of an AgreenSkills' fellowship (under grant agreement number 267196) and by the Laboratory of Excellence ARBRE (Advanced Research on the Biology of Tree and Forest Ecosystems) through the award of a mobility grant (12RW53). D. Saunders was supported by a Leverhulme early career fellowship and a fellowship in computational biology at TGAC, in partnership with the JIC, and strategically supported by the Biotechnology and Biological Sciences Research Council (BBSRC). C. Lorrain is supported by an INRA Contrat Jeune Scientifique and by the Laboratory of Excellence ARBRE. S. Duplessis is supported by the French National Research Agency through the Laboratory of Excellence ARBRE (ANR-12-LABXARBRE-01) and the Young Scientist Grant POPRUST (ANR-2010-JCJC-1709-01). Research at TSL is supported by the Gatsby Charitable Foundation. This project was supported by the Sustainable Crop Production Research for International Development from the BBSRC.

\section{LITERATURE CITED}

Alfano, J. R. 2009. Roadmap for future research on plant pathogen effectors. Mol. Plant Pathol. 10:805-813.

Block, A., Guo, M., Li, G., Elowsky, C., Clemente, T. E., and Alfano, J. R. 2010. The Pseudomonas syringae type III effector HopG1 targets mitochondria, alters plant development and suppresses plant innate immunity. Cell. Microbiol. 12:318-330.

Boller, T., and He, S. Y. 2009. Innate immunity in plants: An arms race between pattern recognition receptors in plants and effectors in microbial pathogens. Science 324:742-744.

Bombarely, A., Rosli, H. G., Vrebalov, J., Moffett, P., Mueller, L. A., and Martin, G. B. 2012. A draft genome sequence of Nicotiana benthamiana to enhance molecular plant-microbe biology research. Mol. Plant Microbe Interact. 25:1523-1530.

Bos, J. I., Kanneganti, T. D., Young, C., Cakir, C., Huitema, E., Win, J., Armstrong, M. R., Birch, P. R., and Kamoun, S. 2006. The C-terminal half of Phytophthora infestans RXLR effector AVR3a is sufficient to trigger R3a-mediated hypersensitivity and suppress INF1-induced cell death in Nicotiana benthamiana. Plant J. 48:165-176.

Bos, J. I., Armstrong, M. R., Gilroy, E. M., Boevink, P. C., Hein, I., Taylor, R. M., Zhendong, T., Engelhardt, S., Vetukuri, R. R., Harrower, B., Dixelius, C., Bryan, G., Sadanandom, A., Whisson, S. C., Kamoun, S., and Birch, P. R. 2010. Phytophthora infestans effector AVR3a is essential for virulence and manipulates plant immunity by stabilizing host E3 ligase CMPG1. Proc. Natl. Acad. Sci. U.S.A. 107:9909-9914.

Bozkurt, T. O., Schornack, S., Win, J., Shindo, T., Ilyas, M., Oliva, R., Cano, L. M., Jones, A. M., Huitema, E., van der Hoorn, R. A., and Kamoun, S. 2011. Phytophthora infestans effector AVRblb2 prevents secretion of a plant immune protease at the haustorial interface. Proc. Natl. Acad. Sci. U.S.A. 108:20832-20837.

Bozkurt, T. O., Schornack, S., Banfield, M. J., and Kamoun, S. 2012. Oomycetes, effectors, and all that jazz. Curr. Opin. Plant Biol. 15:483-492.

Caillaud, M. C., Piquerez, S. J., Fabro, G., Steinbrenner, J., Ishaque, N., Beynon, J., and Jones, J. D. 2012. Subcellular localization of the Hpa RxLR effector repertoire identifies a tonoplast-associated protein HaRxL17 that confers enhanced plant susceptibility. Plant J. 69:252-265.

Caillaud, M. C., Asai, S., Rallapalli, G., Piquerez, S., Fabro, G., and Jones, J. D. 2013. A downy mildew effector attenuates salicylic acid-triggered immunity in Arabidopsis by interacting with the host mediator complex. PLoS Biol. 11:e1001732.

Cantu, D., Segovia, V., MacLean, D., Bayles, R., Chen, X., Kamoun, S., Dubcovsky, J., Saunders, D. G., and Uauy, C. 2013. Genome analyses of the wheat yellow (stripe) rust pathogen Puccinia striiformis f. sp. tritici reveal polymorphic and haustorial expressed secreted proteins as candidate effectors. BMC Genomics 14:270.

Carrie, C., Giraud, E., and Whelan, J. 2009. Protein transport in organelles: Dual targeting of proteins to mitochondria and chloroplasts. FEBS J. 276:1187-1195.

Catanzariti, A. M., Dodds, P. N., Lawrence, G. J., Ayliffe, M. A., and Ellis, J. G. 2006. Haustorially expressed secreted proteins from flax rust are highly enriched for avirulence elicitors. Plant Cell 18:243-256.

Causier, B., Lloyd, J., Stevens, L., and Davies, B. 2012. TOPLESS corepressor interactions and their evolutionary conservation in plants. Plant Signal. Behav. 7:325-328.

Dean, R., Van Kan, J. A., Pretorius, Z. A., Hammond-Kosack, K. E., Di Pietro, A., Spanu, P. D., Rudd, J. J., Dickman, M., Kahmann, R., Ellis, J., and Foster, G. D. 2012. The top 10 fungal pathogens in molecular plant pathology. Mol. Plant Pathol. 13:414-430.

Djamei, A., Schipper, K., Rabe, F., Ghosh, A., Vincon, V., Kahnt, J., Osorio, S., Tohge, T., Fernie, A. R., Feussner, I., Feussner, K., Meinicke, P., Stierhof, Y. D., Schwarz, H., Macek, B., Mann, M., and Kahmann, R. 2011. Metabolic priming by a secreted fungal effector. Nature 478:395-398. 
Dodds, P. N., and Rathjen, J. P. 2010. Plant immunity: Towards an integrated view of plant-pathogen interactions. Nat. Rev. Genet. 11: 539-548.

Dong, S., Stam, R., Cano, L. M., Song, J., Sklenar, J., Yoshida, K., Bozkurt, T. O., Oliva, R., Liu, Z., Tian, M., Win, J., Banfield, M. J., Jones, A. M., van der Hoorn, R. A., and Kamoun, S. 2014. Effector specialization in a lineage of the Irish potato famine pathogen. Science 343:552-555.

Du, J., Rietman, H., and Vleeshouwers, V. G. A. A. 2014. Agroinfiltration and PVX agroinfection in potato and Nicotiana benthamiana. J. Vis. Exp. 83:e50971.

Duplessis, S., Major, I., Martin, F., and Séguin, A. 2009. Poplar and pathogen interactions: Insights from genome-wide analyses of resistance and defense gene families and expression profiling of poplar leaves upon infection with rust. Crit. Rev. Plant Sci. 28:309-34.

Duplessis, S., Cuomo, C. A., Lin, Y. C., Aerts, A., Tisserant, E., VeneaultFourrey, C., Joly, D. L., Hacquard, S., Amselem, J., Cantarel, B. L., Chiu, R., Coutinho, P. M., Feau, N., Field, M., Frey, P., Gelhaye, E., Goldberg, J., Grabherr, M. G., Kodira, C. D., Kohler, A., Kües, U., Lindquist, E. A., Lucas, S. M., Mago, R., Mauceli, E., Morin, E., Murat, C., Pangilinan, J. L., Park, R., Pearson, M., Quesneville, H., Rouhier, N., Sakthikumar, S., Salamov, A. A., Schmutz, J., Selles, B., Shapiro, H., Tanguay, P., Tuskan, G. A., Henrissat, B., Van de Peer, Y., Rouzé, P., Ellis, J. G., Dodds, P. N., Schein, J. E., Zhong, S., Hamelin, R. C., Grigoriev, I. V., Szabo, L. J., and Martin, F. 2011a. Obligate biotrophy features unraveled by the genomic analysis of rust fungi. Proc. Natl. Acad. Sci. U.S.A. 108: 9166-9171.

Duplessis, S., Hacquard, S., Delaruelle, C., Tisserant, E., Frey, P., Martin, F., and Kohler, A. 2011b. Melampsora larici-populina transcript profiling during germination and timecourse infection of poplar leaves reveals dynamic expression patterns associated with virulence and biotrophy. Mol. Plant Microbe Interact. 24:808-818.

Duplessis, S., Joly, D. L., and Dodds, P. N. 2012. Rust effectors. Pages 155-193 in: Effectors in Plant-Microbe Interactions. F. Martin and S. Kamoun, eds. Wiley-Blackwell, Chichester, U.K.

Garnica, D. P., Nemri, A., Upadhyaya, N. M., Rathjen, J. P., and Dodds, P. N. 2014. The ins and outs of rust haustoria. PLoS Pathog. 10: e1004329.

Haas, B. J., Kamoun, S., Zody, M. C., Jiang, R. H., Handsaker, R. E., Cano, L. M., Grabherr, M., Kodira, C. D., Raffaele, S., Torto-Alalibo, T., Bozkurt, T. O., Ah-Fong, A. M., Alvarado, L., Anderson, V. L., Armstrong, M. R., Avrova, A., Baxter, L., Beynon, J., Boevink, P. C., Bollmann, S. R., Bos, J. I., Bulone, V., Cai, G., Cakir, C., Carrington, J. C., Chawner, M., Conti, L., Costanzo, S., Ewan, R., Fahlgren, N., Fischbach, M. A., Fugelstad, J., Gilroy, E. M., Gnerre, S., Green, P. J., Grenville-Briggs, L. J., Griffith, J., Grünwald, N. J., Horn, K., Horner, N. R., Hu, C. H., Huitema, E., Jeong, D. H., Jones, A. M., Jones, J. D., Jones, R. W., Karlsson, E. K., Kunjeti, S. G., Lamour, K., Liu, Z., Ma, L., Maclean, D., Chibucos, M. C., McDonald, H., McWalters, J., Meijer, H. J., Morgan, W., Morris, P. F., Munro, C. A., O’Neill, K., OspinaGiraldo, M., Pinzón, A., Pritchard, L., Ramsahoye, B., Ren, Q., Restrepo, S., Roy, S., Sadanandom, A., Savidor, A., Schornack, S., Schwartz, D. C., Schumann, U. D., Schwessinger, B., Seyer, L., Sharpe, T., Silvar, C., Song, J., Studholme, D. J., Sykes, S., Thines, M., van de Vondervoort, P. J., Phuntumart, V., Wawra, S., Weide, R., Win, J., Young, C., Zhou, S., Fry, W., Meyers, B. C., van West, P., Ristaino, J., Govers, F., Birch, P. R., Whisson, S. C., Judelson, H. S., and Nusbaum, C. 2009. Genome sequence and analysis of the Irish potato famine pathogen Phytophthora infestans. Nature 461:393-398.

Hacquard, S., Delaruelle, C., Legué, V., Tisserant, E., Kohler, A., Frey, P., Martin, F., and Duplessis, S. 2010. Laser capture microdissection of uredinia formed by Melampsora larici-populina revealed a transcriptional switch between biotrophy and sporulation. Mol. Plant Microbe Interact. 23:1275-1286.

Hacquard, S., Petre, B., Frey, P., Hecker, A., Rouhier, N., and Duplessis, S. 2011. The poplar-poplar rust interaction: Insights from genomics and transcriptomics. J. Pathogens 2011:716041. Published online.

Hacquard, S., Joly, D. L., Lin, Y. C., Tisserant, E., Feau, N., Delaruelle, C., Legué, V., Kohler, A., Tanguay, P., Petre, B., Frey, P., Van de Peer, Y., Rouzé, P., Martin, F., Hamelin, R. C., and Duplessis, S. 2012. A comprehensive analysis of genes encoding small secreted proteins identifies candidate effectors in Melampsora larici-populina (poplar leaf rust). Mol. Plant Microbe Interact. 25:279-293.

Hogenhout, S. A., Van der Hoorn, R. A., Terauchi, R., and Kamoun, S. 2009. Emerging concepts in effector biology of plant-associated organisms. Mol. Plant Microbe Interact. 22:115-122.

Jelenska, J., Yao, N., Vinatzer, B. A., Wright, C. M., Brodsky, J. L., and Greenberg, J. T. 2007. A J domain virulence effector of Pseudomonas syringae remodels host chloroplasts and suppresses defenses. Curr. Biol. 17:499-508.
Joly, D. L., Feau, N., Tanguay, P., and Hamelin, R. C. 2010. Comparative analysis of secreted protein evolution using expressed sequence tags from four poplar leaf rusts (Melampsora spp.). BMC Genomics 11:422.

Kamoun, S. 2007. Groovy times: Filamentous pathogen effectors revealed. Curr. Opin. Plant Biol. 10:358-365.

Kemen, E., Kemen, A. C., Rafiqi, M., Hempel, U., Mendgen, K., Hahn, M., and Voegele, R. T. 2005. Identification of a protein from rust fungi transferred from haustoria into infected plant cells. Mol. Plant Microbe Interact. 18:1130-1139.

Kemen, E., Kemen, A., Ehlers, A., Voegele, R., and Mendgen, K. 2013. A novel structural effector from rust fungi is capable of fibril formation. Plant J. 75:767-780.

Li, G., Froehlich, J. E., Elowsky, C., Msanne, J., Ostosh, A. C., Zhang, C., Awada, T., and Alfano, J. R. 2014. Distinct Pseudomonas type-III effectors use a cleavable transit peptide to target chloroplasts. Plant J. 77: 310-321.

Major, I. T., Nicole, M. C., Duplessis, S., and Séguin, A. 2010. Photosynthetic and respiratory changes in leaves of poplar elicited by rust infection. Photosynth. Res. 104:41-48.

Mak, A. N., Bradley, P., Cernadas, R. A., Bogdanove, A. J., and Stoddard, B. L. 2012. The crystal structure of TAL effector PthXo1 bound to its DNA target. Science 335:716-719.

McLellan, H., Boevink, P. C., Armstrong, M. R., Pritchard, L., Gomez, S., Morales, J., Whisson, S. C., Beynon, J. L., and Birch, P. R. 2013. An RxLR effector from Phytophthora infestans prevents re-localisation of two plant NAC transcription factors from the endoplasmic reticulum to the nucleus. PLoS Pathog. 9:e1003670.

Mellacheruvu, D., Wright, Z., Couzens, A. L., Lambert, J. P., St-Denis, N. A., Li, T., Miteva, Y. V., Hauri, S., Sardiu, M. E., Low, T. Y., Halim, V. A., Bagshaw, R. D., Hubner, N. C., Al-Hakim, A., Bouchard, A., Faubert, D., Fermin, D., Dunham, W. H., Goudreault, M., Lin, Z. Y., Badillo, B. G., Pawson, T., Durocher, D., Coulombe, B., Aebersold, R., Superti-Furga, G., Colinge, J., Heck, A. J., Choi, H., Gstaiger, M., Mohammed, S., Cristea, I. M., Bennett, K. L., Washburn, M. P., Raught, B., Ewing, R. M., Gingras, A. C., and Nesvizhskii, A. I. 2013. The CRAPome: A contaminant repository for affinity purification-mass spectrometry data. Nat. Methods 10:730-736.

Miteva, Y. V., Budayeva, H. G., and Cristea, I. M. 2013. Proteomics-based methods for discovery, quantification, and validation of protein-protein interactions. Anal. Chem. 85:749-768.

Mukhtar, M. S., Carvunis, A. R., Dreze, M., Epple, P., Steinbrenner, J., Moore, J., Tasan, M., Galli, M., Hao, T., Nishimura, M. T., Pevzner, S. J., Donovan, S. E., Ghamsari, L., Santhanam, B., Romero, V., Poulin, M. M., Gebreab, F., Gutierrez, B. J., Tam, S., Monachello, D., Boxem, M., Harbort, C. J., McDonald, N., Gai, L., Chen, H., He, Y., European Union Effectoromics Consortium,Vandenhaute, J., Roth, F. P., Hill, D. E., Ecker, J. R., Vidal, M., Beynon, J., Braun, P., and Dangl, J. L. 2011. Independently evolved virulence effectors converge onto hubs in a plant immune system network. Science 333:596-601.

Nelson, B. K., Cai, X., and Nebenführ, A. 2007. A multicolored set of in vivo organelle markers for co-localization studies in Arabidopsis and other plants. Plant J. 51:1126-1136.

Nemri, A., Saunders, D. G., Anderson, C., Upadhyaya, N. M., Win, J., Lawrence, G. J., Jones, D. A., Kamoun, S., Ellis, J. G., and Dodds, P. N. 2014. The genome sequence and effector complement of the flax rust pathogen Melampsora lini. Front. Plant Sci. 5:98.

Oh, S. K., Young, C., Lee, M., Oliva, R., Bozkurt, T. O., Cano, L. M., Win, J., Bos, J. I., Liu, H. Y., van Damme, M., Morgan, W., Choi, D., Van der Vossen, E. A., Vleeshouwers, V. G., and Kamoun, S. 2009. In planta expression screens of Phytophthora infestans RXLR effectors reveal diverse phenotypes, including activation of the Solanum bulbocastanum disease resistance protein Rpi-blb2. Plant Cell 21:2928-2947.

Park, C. H., Chen, S., Shirsekar, G., Zhou, B., Khang, C. H., Songkumarn, P., Afzal, A. J., Ning, Y., Wang, R., Bellizzi, M., Valent, B., and Wang, G. L. 2012. The Magnaporthe oryzae effector AvrPiz-t targets the RING E3 ubiquitin ligase APIP6 to suppress pathogen-associated molecular pattern-triggered immunity in rice. Plant Cell 24:4748-4762.

Pauwels, L., Barbero, G. F., Geerinck, J., Tilleman, S., Grunewald, W., Pérez, A. C., Chico, J. M., Bossche, R. V., Sewell, J., Gil, E., GarcíaCasado, G., Witters, E., Inzé, D., Long, J. A., De Jaeger, G., Solano, R., and Goossens, A. 2010. NINJA connects the co-repressor TOPLESS to jasmonate signalling. Nature 464:788-791.

Pégeot, H., Koh, C.-S., Petre, B., Mathiot, S., Duplessis, S., Hecker, A., Didierjean, C., and Rouhier, N. 2014. The poplar Phi class glutathione transferase: Expression, activity and structure of GSTF1. Front. Plant Sci. 5:712.

Pennisi, E. 2010. Armed and dangerous. Science 327:804-805.

Petre, B., and Kamoun, S. 2014. How do filamentous pathogens deliver effector proteins into plant cells? PLoS Biol. 12:e1001801. 
Petre, B., Morin, E., Tisserant, E., Hacquard, S., Da Silva, C., Poulain, J., Delaruelle, C., Martin, F., Rouhier, N., Kohler, A., and Duplessis, S. 2012. RNA-Seq of early-infected poplar leaves by the rust pathogen Melampsora larici-populina uncovers PtSultr3;5, a fungal-induced host sulfate transporter. PLoS ONE 7:e44408.

Petre, B., Joly, D. L., and Duplessis, S. 2014. Effector proteins of rust fungi. Front. Plant Sci. 5:416.

Raffaele, S., Win, J., Cano, L. M., and Kamoun, S. 2010. Analyses of genome architecture and gene expression reveal novel candidate virulence factors in the secretome of Phytophthora infestans. BMC Genomics 11:637.

Rafiqi, M., Gan, P. H., Ravensdale, M., Lawrence, G. J., Ellis, J. G., Jones, D. A., Hardham, A. R., and Dodds, P. N. 2010. Internalization of flax rust avirulence proteins into flax and tobacco cells can occur in the absence of the pathogen. Plant Cell 22:2017-2032.

Rafiqi, M., Ellis, J. G., Ludowici, V. A., Hardham, A. R., and Dodds, P. N. 2012. Challenges and progress towards understanding the role of effectors in plant-fungal interactions. Curr. Opin. Plant Biol. 15:477-482.

Rodríguez-Herva, J. J., González-Melendi, P., Cuartas-Lanza, R., AntúnezLamas, M., Río-Alvarez, I., Li, Z., López-Torrejón, G., Díaz, I., Del Pozo, J. C., Chakravarthy, S., Collmer, A., Rodríguez-Palenzuela, P., and López-Solanilla, E. 2012. A bacterial cysteine protease effector protein interferes with photosynthesis to suppress plant innate immune responses. Cell. Microbiol. 14:669-681.

Rovenich, H., Boshoven, J. C., and Thomma, B. P. 2014. Filamentous pathogen effector functions: Of pathogens, hosts and microbiomes. Curr. Opin. Plant Biol. 20:96-103.

Saunders, D. G., Win, J., Cano, L. M., Szabo, L. J., Kamoun, S., and Raffaele, S. 2012. Using hierarchical clustering of secreted protein families to classify and rank candidate effectors of rust fungi. PLoS ONE 7:e29847.

Schmidt, S. M., and Panstruga, R. 2011. Pathogenomics of fungal plant parasites: What have we learnt about pathogenesis? Curr. Opin. Plant Biol. 14:392-399.

Schornack, S., van Damme, M., Bozkurt, T. O., Cano, L. M., Smoker, M., Thines, M., Gaulin, E., Kamoun, S., and Huitema, E. 2010. Ancient class of translocated oomycete effectors targets the host nucleus. Proc. Natl. Acad. Sci. U.S.A. 107:17421-17426.

Searle, B. C. 2010. Scaffold: A bioinformatic tool for validating MS/MSbased proteomic studies. Proteomics 10:1265-1269.

Song, J., Win, J., Tian, M., Schornack, S., Kaschani, F., Ilyas, M., van der Hoorn, R. A., and Kamoun, S. 2009. Apoplastic effectors secreted by two unrelated eukaryotic plant pathogens target the tomato defense protease Rcr3. Proc. Natl. Acad. Sci. U.S.A. 106:1654-1659.

Stam, R., Jupe, J., Howden, A. J., Morris, J. A., Boevink, P. C., Hedley, P. E., and Huitema, E. 2013. Identification and characterisation CRN effectors in Phytophthora capsici shows modularity and functional diversity. PLoS ONE 8:e59517.

Teixeira, P. F., and Glaser, E. 2013. Processing peptidases in mitochondria and chloroplasts. Biochim. Biophys. Acta 1833:360-370.

Torto, T. A., Li, S., Styer, A., Huitema, E., Testa, A., Gow, N. A., van West, P., and Kamoun, S. 2003. EST mining and functional expression assays identify extracellular effector proteins from the plant pathogen Phytophthora. Genome Res. 13:1675-1685.

Tuskan, G. A., Difazio, S., Jansson, S., Bohlmann, J., Grigoriev, I., Hellsten, U., Putnam, N., Ralph, S., Rombauts, S., Salamov, A., Schein, J., Sterck, L., Aerts, A., Bhalerao, R. R., Bhalerao, R. P., Blaudez, D., Boerjan, W., Brun, A., Brunner, A., Busov, V., Campbell, M., Carlson, J., Chalot, M., Chapman, J., Chen, G. L., Cooper, D., Coutinho, P. M., Couturier, J., Covert, S., Cronk, Q., Cunningham, R., Davis, J., Degroeve, S., Déjardin, A., Depamphilis, C., Detter, J., Dirks, B., Dubchak, I., Duplessis, S., Ehlting, J., Ellis, B., Gendler, K., Goodstein, D., Gribskov, M., Grimwood, J., Groover, A., Gunter, L., Hamberger, B., Heinze, B., Helariutta, Y., Henrissat, B., Holligan, D., Holt, R., Huang, W., IslamFaridi, N., Jones, S., Jones-Rhoades, M., Jorgensen, R., Joshi, C., Kangasjärvi, J., Karlsson, J., Kelleher, C., Kirkpatrick, R., Kirst, M.,
Kohler, A., Kalluri, U., Larimer, F., Leebens-Mack, J., Leplé, J. C., Locascio, P., Lou, Y., Lucas, S., Martin, F., Montanini, B., Napoli, C., Nelson, D. R., Nelson, C., Nieminen, K., Nilsson, O., Pereda, V., Peter, G., Philippe, R., Pilate, G., Poliakov, A., Razumovskaya, J., Richardson, P., Rinaldi, C., Ritland, K., Rouzé, P., Ryaboy, D., Schmutz, J., Schrader, J., Segerman, B., Shin, H., Siddiqui, A., Sterky, F., Terry, A., Tsai, C. J., Uberbacher, E., Unneberg, P., Vahala, J., Wall, K., Wessler, S., Yang, G., Yin, T., Douglas, C., Marra, M., Sandberg, G., Van de Peer, Y., and Rokhsar, D. 2006. The genome of black cottonwood, Populus trichocarpa (Torr. \& Gray). Science 313:1596-1604.

Vleeshouwers, V. G., Rietman, H., Krenek, P., Champouret, N., Young, C., Oh, S. K., Wang, M., Bouwmeester, K., Vosman, B., Visser, R. G., Jacobsen, E., Govers, F., Kamoun, S., and Van der Vossen, E. A. 2008. Effector genomics accelerates discovery and functional profiling of potato disease resistance and Phytophthora infestans avirulence genes. PLoS ONE 3:e2875.

Wang, Y., Li, J., Hou, S., Wang, X., Li, Y., Ren, D., Chen, S., Tang, X., and Zhou, J. M. 2010. A Pseudomonas syringae ADP-ribosyltransferase inhibits Arabidopsis mitogen-activated protein kinase kinases. Plant Cell 22:2033-2044

Wang, Q., Han, C., Ferreira, A. O., Yu, X., Ye, W., Tripathy, S., Kale, S. D., Gu, B., Sheng, Y., Sui, Y., Wang, X., Zhang, Z., Cheng, B., Dong, S., Shan, W., Zheng, X., Dou, D., Tyler, B. M., and Wang, Y. 2011. Transcriptional programming and functional interactions within the Phytophthora sojae RXLR effector repertoire. Plant Cell 23:2064-2086.

Weber, E., Engler, C., Gruetzner, R., Werner, S., and Marillonnet, S. 2011. A modular cloning system for standardized assembly of multigene constructs. PLoS ONE 6:e16765.

Weßling, R., Epple, P., Altmann, S., He, Y., Yang, L., Henz, S. R., McDonald, N., Wiley, K., Bader, K. C., Gläßer, C., Mukhtar, M. S., Haigis, S., Ghamsari, L., Stephens, A. E., Ecker, J. R., Vidal, M., Jones, J. D., Mayer, K. F., Ver Loren van Themaat, E., Weigel, D., SchulzeLefert, P., Dangl, J. L., Panstruga, R., and Braun, P. 2014. Convergent targeting of a common host protein-network by pathogen effectors from three kingdoms of life. Cell Host Microbe 16:364-375.

Whisson, S. C., Boevink, P. C., Moleleki, L., Avrova, A. O., Morales, J. G., Gilroy, E. M., Armstrong, M. R., Grouffaud, S., van West, P., Chapman, S., Hein, I., Toth, I. K., Pritchard, L., and Birch, P. R. 2007. A translocation signal for delivery of oomycete effector proteins into host plant cells. Nature 450:115-118.

Win, J., Kamoun, S., and Jones, A. M. 2011. Purification of effector-target protein complexes via transient expression in Nicotiana benthamiana. Methods Mol. Biol. 712:181-194.

Win, J., Chaparro-Garcia, A., Belhaj, K., Saunders, D. G., Yoshida, K., Dong, S., Schornack, S., Zipfel, C., Robatzek, S., Hogenhout, S. A., and Kamoun, S. 2012. Effector biology of plant-associated organisms: Concepts and perspectives. Cold Spring Harb. Symp. Quant. Biol. 77: 235-247.

Xing, W., Zou, Y., Liu, Q., Liu, J., Luo, X., Huang, Q., Chen, S., Zhu, L., Bi, R., Hao, Q., Wu, J. W., Zhou, J. M., and Chai, J. 2007. The structural basis for activation of plant immunity by bacterial effector protein AvrPto. Nature 449:243-247.

\section{AUTHOR-RECOMMENDED INTERNET RESOURCES}

ChloroP 1.1 server: http://www.cbs.dtu.dk/services/ChloroP

Joint Genome Institute Genome portal:

http://genomeportal.jgi-psf.org

Fiji image processing package: http://fiji.sc/Fiji

Phytozome Populus trichocarpa site: http://www.phytozome.net/poplar P. trichocarpa proteome v3.0: http://phytozome.jgi.doe.gov

Sol Genomics Network: http://solgenomics.net

SynBio@TSL website: http://synbio.tsl.ac.uk 